\title{
Case report: Delayed presentation of postural headache in an adolescent girl after microscopic lumbar discectomy
}

\author{
[Survenue retardée de céphalées posturales chez une adolescente à la suite d'une \\ discectomie lombaire microscopique]
}

Anjana Kundu MD, ${ }^{*}$ Yuko Sano MD, ${ }^{*}$ Paul S. Pagel MD PhD $\dagger$

Purpose: To discuss the diagnostic and therapeutic challenges presented by an adolescent girl with delayed postural headaches and photophobia that occurred three months after an apparently uncomplicated microscopic lumbar discectomy.

Clinical features: A previously healthy girl was admitted to our hospital with a one-week history of an unremitting, frontalretroorbital postural headache and photophobia. Three months before admission, the patient had undergone a L5-SI left hemilaminotomy and foraminotomy with microdiscectomy for excision of a herniated intervertebral disc. Conservative treatment failed to provide symptomatic relief. Cranial magnetic resonance imaging showed enhancement of the pachymeninges, consistent with intracranial hypotension. A chronic cerebrospinal leak was identified by high-resolution computed tomography (CT) myelography. Epidural blood patches were performed, with and without CT guidance, that provided temporary relief of the patient's symptoms; however, direct suture plication of the dural tear was eventually required for definitive treatment.

Conclusion: This case emphasizes that delayed presentation of dural injury may occur after lumbar surgery and describes the potential therapeutic implications for this unusual complication.

CAN J ANESTH 2008 / 55: $10 /$ pp 696-701
Objectif : Discuter le diagnostic et les défis thérapeutiques posés par une adolescente présentant des céphalées posturales différées et de la photophobie trois mois après une discectomie lombaire microscopique apparemment sans complications.

Éléments cliniques: Après une semaine de céphalées posturales frontales rétro-orbitaires accompagnée de photophobie, une jeune fille précédemment saine a été admise à notre hôpital. Trois mois avant son admission, la patiente avait subi une hémilaminectomie gauche L5-SI et une foraminotomie par microdiscectomie pour l'excision d'un disque intervertébral hernié. Le traitement traditionnel n'a pas procuré de soulagement des symptômes. Une imagerie par résonance magnétique crânienne a montré une croissance de la dure-mère, compatible avec de l'hypotension intracrânienne. Une fuite chronique du liquide céphalorachidien a été détectée grâce à une myélographie par tomodensitométrie à haute résolution. Des blood patches périduraux ont été réalisés avec et sans guidage tomodensitométrique, ce qui a permis de soulager les symptômes de la patiente; toutefois, une plicature directe de la déchirure durale par suture a finalement été nécessaire pour obtenir un traitement définitif.

Conclusion : Ce cas souligne le fait qu'une lésion durale peut survenir de façon différée après une chirurgie lombaire et décrit les implications thérapeutiques possibles de cette complication inhabituelle.

From the Department of Anesthesiology and Pain Medicine, ${ }^{*}$ Children's Hospital and Regional Medical Center and University of Washington School of Medicine, Seattle, Washington; and the Anesthesia Service, $\dagger$ the Clement J. Zablocki Veterans Affairs Medical Center, Milwaukee, Wisconsin, USA.

Address correspondence to: Dr. Anjana Kundu, Department of Anesthesiology and Pain Medicine, M/S W9824, Children's Hospital and Regional Medical Center, 4800 Sand Point Way NE, Seattle, Washington 98105, USA. Phone: 206-987-2704; Fax: 206-987-3935; E-mail: anjana.kundu@seattlechildrens.org

This work was supported entirely by departmental funds.

Conflicts of interest: None declared.

Accepted for publication June 10, 2008.

Revision accepted July 16, 2008. 


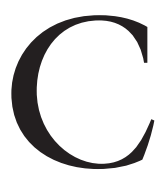

erebrospinal fluid (CSF) leak, due to an inadvertent durotomy, is a well-known complication of spine surgery, with a reported incidence ranging from $1 \%$ to $17 \%{ }^{1-4}$ Incidental dural tears most often occur during open or repeat lumbar procedures in adults, ${ }^{5}$ but have rarely been described during initial lumbar microscopic surgery in pediatric or adolescent patients. ${ }^{3,6}$ Inadvertent durotomy is usually recognized and corrected intraoperatively, ${ }^{7,8}$ but compromise of dural integrity may not be identified until the patient develops symptoms some time after the procedure. A chronic CSF leak produced by a dural tear is associated with substantial clinical morbidity ${ }^{1,9}$ and has been identified as the second most frequently named occurrence in medical malpractice cases involving lumbar spine surgery. ${ }^{10}$ Delayed presentation of unrecognized durotomy two weeks after surgery has been previously described. ${ }^{6}$ In this report, we discuss our evaluation and management of an adolescent girl who presented with recurrent postural headaches and photophobia occurring three months after an apparently uncomplicated microscopic lumbar discectomy. A chronic CSF leak was identified by high-resolution computed tomography (CT) myelography. Epidural blood patches were performed, with and without CT guidance, that provided temporary relief of the patient's symptoms, but direct suture plication of the dural tear was eventually required for definitive treatment. The case emphasizes that delayed presentation of dural injury may occur after lumbar surgery and describes the potential therapeutic implications for this unusual complication. Consent for publication of this report was obtained in accordance with the local institutional guidelines where the patient received her care.

\section{Case report}

A previously healthy, athletic 15 -yr-old girl $(62 \mathrm{~kg}$, $162 \mathrm{~cm}$ ) was admitted to our hospital with a oneweek history of an unremitting, frontal-retroorbital postural headache and photophobia that began one day after playing basketball. Three months before the admission, the patient had undergone an apparently uncomplicated L5-S1 left hemilaminotomy and foraminotomy with microdiscectomy, for excision of a herniated intervertebral disc. Initially, the patient's pediatrician evaluated and treated her symptoms. The patient denied a history of headaches, and the physical examination revealed no new focal neurologic or ophthalmologic deficits. Conservative treatment, including bed rest, recumbent posture, hydration, and oral drug therapy (ibuprofen, acetaminophen, and oxycodone), failed to provide any substantial symptomatic relief.

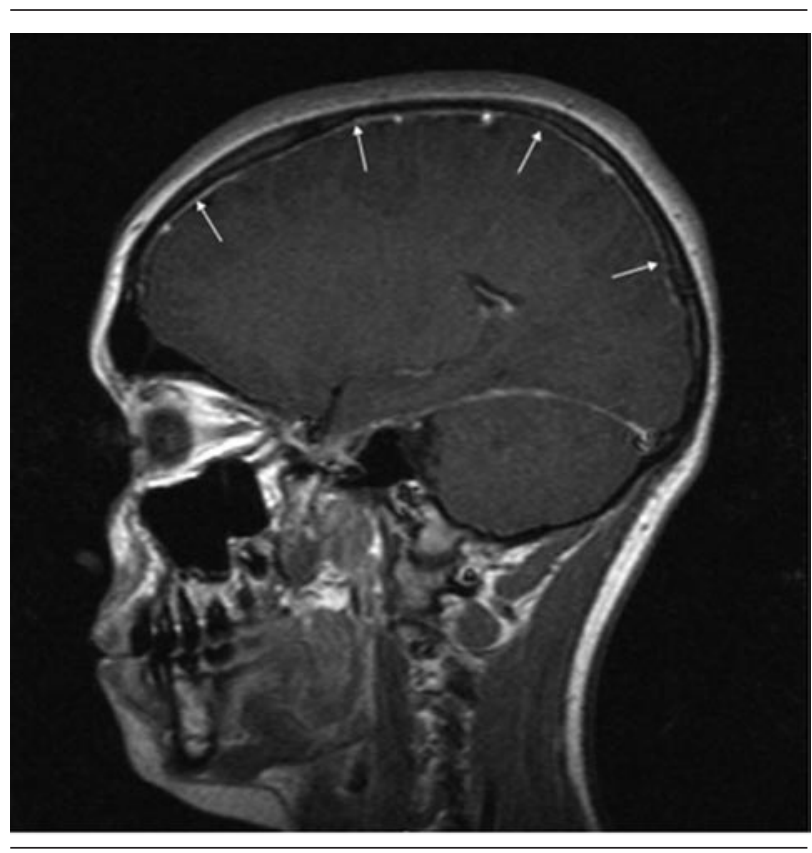

FIGURE I Cranial MRI image without angiographic contrast demonstrating meningeal thickening and enhancement (arrows) suggestive of intracranial hypotension.

A cranial CT scan, with and without angiographic contrast, was normal. The patient was referred to her neurosurgeon for further care. A cranial magnetic resonance imaging (MRI) study showed mild thickening and enhancement of the pachymeninges, consistent with intracranial hypotension (Figure 1). Magnetic resonance imaging of the lumbar spine was obtained that demonstrated mild persistent disc extrusion at L5-S1, but revealed no evidence of a pseudomeningocele, nerve root compression, or root displacement. As the presumptive etiology, the postural component of the headache strongly suggested a CSF leak resulting from inadvertent durotomy. Intravenous fluids, caffeine, ketorolac, and morphine failed to relieve the patient's symptoms. A high resolution CT myelogram demonstrated focal contrast extravasation at L5-S1, consistent with a CSF leak in the region of the previous left hemilaminotomy (Figure 2).

The pain management service (A.K. and Y.S.) was consulted for treatment of the refractory headache. An L3-4 epidural blood patch ( $15 \mathrm{~mL} ; 0.25$ $\left.\mathrm{mL} \cdot \mathrm{kg}^{-1}\right)$ was performed under conscious sedation using midazolam $(3 \mathrm{mg} i \mathrm{v})$ and fentanyl $(50 \mu \mathrm{g} i \mathrm{v})$. The epidural blood patch partially improved, but did not completely eliminate, the patient's symptoms. She remained unable to sit upright or ambulate for more than 30 min without a recurrence of the headache, and she was unable to regularly attend classes at her 


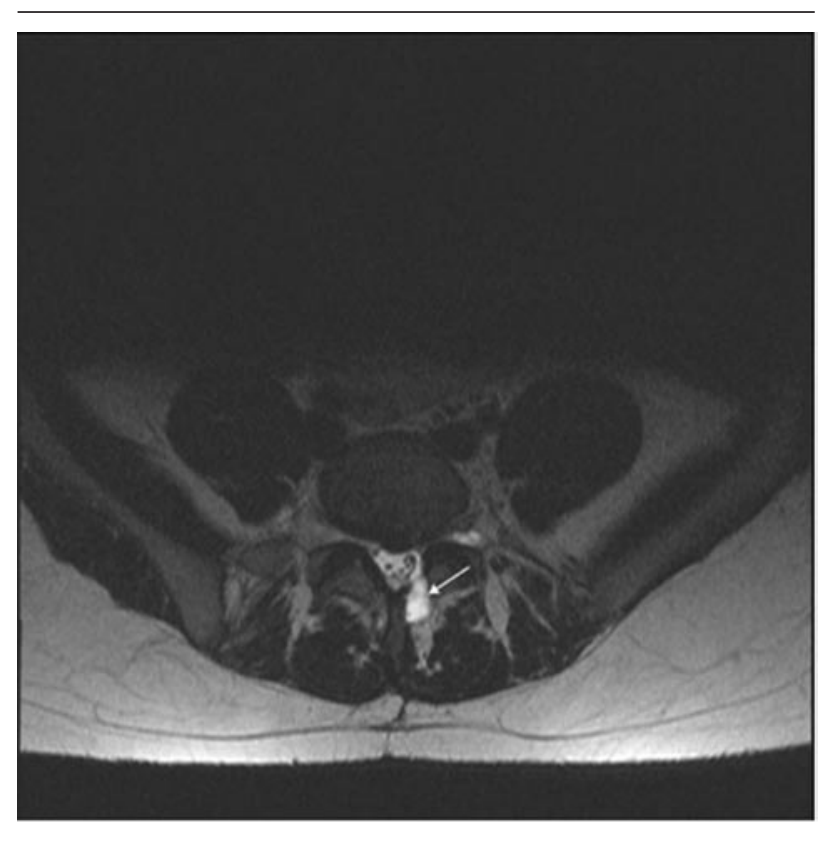

FIGURE 2 High resolution computed tomography myelogram demonstrating extravasation of contrast consistent with a pseudomeningocele (arrow) at L5-S1 level.

high school. Once more using intravenous conscious sedation, a second epidural blood patch with blood $(13.5 \mathrm{~mL})$ and a radioopaque contrast agent $(1.5$ $\mathrm{mL}$; Isovue M300, Bracco Diagnostics, Princeton, NJ, USA) was performed under CT guidance in prone position at the L5-S1 interspace. Computed tomography imaging confirmed epidural spread of contrast throughout the L5-SI interspace, including the region of the documented CSF leak (Figure 3). The patient's headache resolved completely after this second procedure. Unfortunately, her postural headache and photophobia abruptly returned one week later after playing basketball. The headache symptoms were accompanied by a simultaneous recurrence of left L5-S1 radicular pain that was nearly identical to her complaints before the original surgery. Another lumbar-sacral MRI study was obtained that demonstrated scarring, residual disc herniation, and a pseudomeningocele at L5-S1 (Figure 4). The patient was taken to the operating room where the original midline lumbar incision was opened, and extensive scarring of the lumbar-sacral dorsal fascia and around the L5-S1 nerve roots was resected. Remnants of the L5 lamina and spinous process were excised, and bilateral L4 to S1 laminectomies were performed. A $0.5 \mathrm{~cm}$ durotomy was identified that was primarily repaired by plication using a 4.0 silk suture. The patient made an uneventful postoperative recovery. She reported

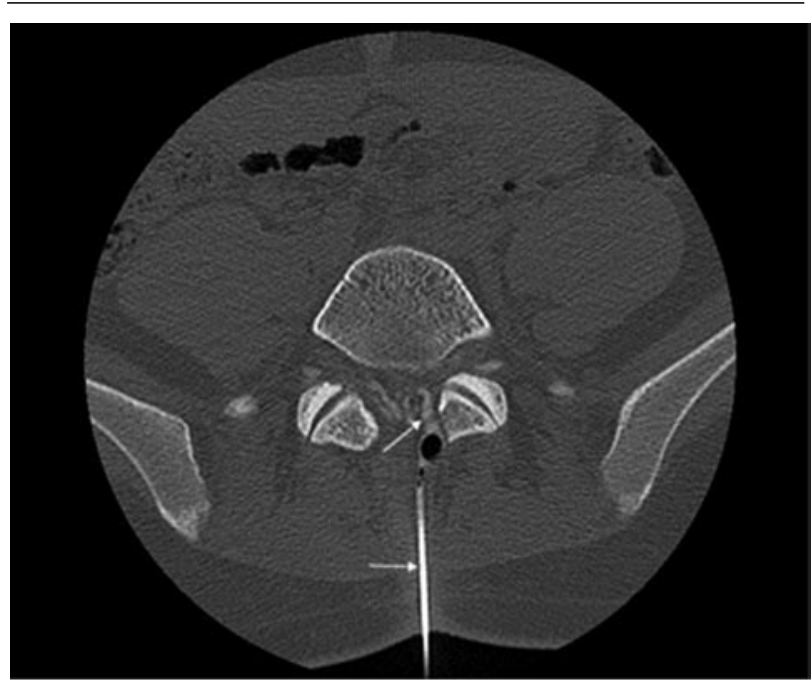

FIGURE 3 Computed tomography guided epidural blood patch image demonstrating epidural needle (lower arrow) and epidural spread of contrast at L5-S1 level (upper arrow).

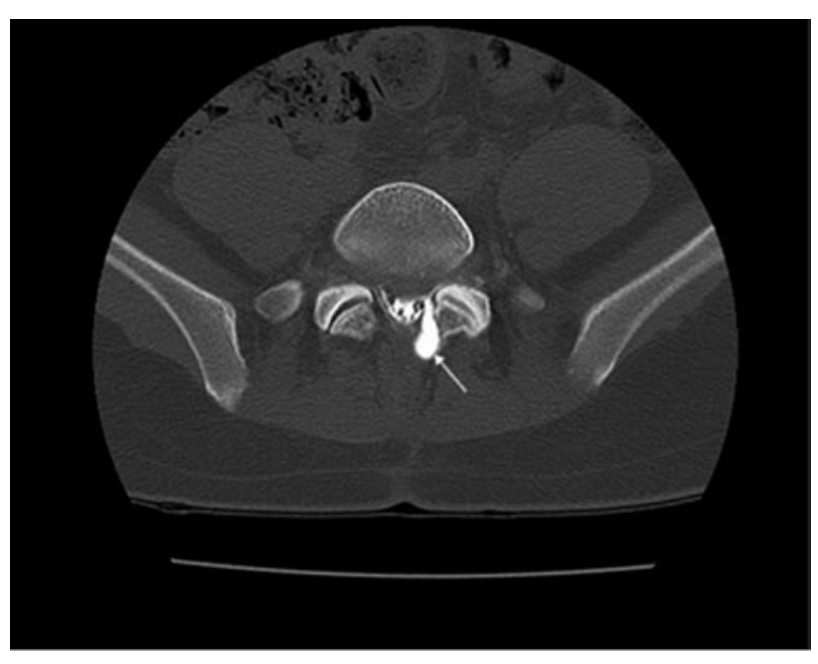

FIGURE $4 \quad \mathrm{~T}_{2}$ weighted magnetic resonance imaging without contrast demonstrating a pseudomeningocele (arrow) and persistence of a focal central disc protrusion at L5-S1.

complete resolution of her postural headache and left lower extremity radicular symptoms two and four weeks, respectively, after surgery.

\section{Discussion}

Delayed CSF leak, resulting from unrecognized durotomy, is an unusual complication of lumbar spine surgery and has rarely been reported after microscopic lumbar discectomy in adolescent patients. In a review of 2,144 adults undergoing spine surgery, 
the reported incidence of clinically significant CSF leaks, resulting from inadvertent durotomy that were not identified and repaired intraoperatively, was $0.28 \% .^{7}$ Inadvertent durotomy occurs more frequently in patients undergoing revision procedures compared to primary operations. Khan et al. ${ }^{5}$ reported that the incidence of dural tears was $7.6 \%$ in patients undergoing primary operations compared to $15.9 \%$ in patients undergoing revision surgery for degenerative disease of the lumbar spine. Similarly, in another prospective study of 1,549 patients, dural tears occurred in $3.5 \%$ of patients undergoing primary discectomy $v s 13.2 \%$ of patients undergoing revision discectomy. ${ }^{8}$ Reoperation for intraoperatively unrecognized or inadequately repaired incidental durotomy was required in $1.8 \%$ of patients. ${ }^{5}$ Incidental durotomy also occurred more frequently in open $v s$ microscopic operations $s^{3}$ and was directly correlated with a number of previous spine surgeries. ${ }^{4}$ Thus, our adolescent patient without a history of lumbar surgery, who originally underwent a microscopic discectomy, appeared to be at relatively low risk of sustaining an inadvertent durotomy. In contrast to surgically-induced durotomy, a dural tear occurring later after spine surgery may result from residual bone fragments or from increases in CSF pressure occurring during valsalva-inducing maneuvers or physical activity in the presence of a weakened dural sac. ${ }^{9}$ Such risk factors may have contributed to the development of our physically active patient's symptoms three months after her original operation. Late onset durotomy after discectomy was also previously reported in patients receiving ADCON-L, ${ }^{6}$ a porcine-derived polyglycan that has been advocated in lumbar surgery to reduce postoperative peridural fibrosis and adhesions. ADCON-L was not used in our patient.

Spontaneous spinal CSF leak resulting in spontaneous intracranial hypotension $(\mathrm{SIH})$ and orthostatic headache may occur in the absence of obvious loss of dural integrity produced by trauma or previous surgery. ${ }^{11,12}$ The clinical presentation of SIH may be very similar to that experienced by our patient. ${ }^{11,12}$ The incidence of SIH was recently estimated at $0.005 \%$ per patient year. ${ }^{12}$ Spontaneous intracranial hypotension has rarely been reported in adolescents ${ }^{13,14}$ and is more commonly encountered in adult women with predisposing factors (e.g., connective tissue disease, Marfan's syndrome, Ehlers-Danlos syndrome) between the third and fifth decades of life. ${ }^{12}$ Thus, it appears unlikely that SIH was responsible for our adolescent patient's symptoms, especially in view of the antecedent surgical intervention.
Magnetic resonance imaging was previously reported to be very reliable in identifying the presence and location of CSF leaks in patients with CSF fistulae or $\mathrm{SIH}$, even in the absence of active drainage of CSF. ${ }^{15}$ Nevertheless, the current case emphasizes that routine neuroradiology alone may be inadequate to define the source of a delayed CSF leak resulting from incidental durotomy. The initial CT and MRI studies obtained in our patient did not demonstrate a pseudomeningocele (which often suggests the location of the durotomy or CSF leak), but these negative studies did not reliably exclude CSF leak from the differential diagnosis of postural headache and photophobia. Indeed, our patient's cranial MRI demonstrated diffuse meningeal enhancement, which occurs as a result of dural venous dilatation concomitant with reduced CSF pressure and volume consistent with chronic loss of CSF. ${ }^{16}$ The current case further emphasizes that identification of the precise location of the CSF leak is crucial for providing effective treatment. ${ }^{17}$ High resolution CT myelography was previously shown to definitively demonstrate the durotomy site after lumbar surgery, ${ }^{18}$ and this technique was also used to establish the diagnosis of a dural tear and to identify the location of the CSF leak in our patient. Interestingly, a pseudomeningocele was later identified during the subsequent lumbar-sacral MRI study after our patient's symptoms recurred, suggesting that sufficient time had elapsed to allow a contained CSF accumulation outside the subarachnoid space.

The use of an epidural blood patch for the management of postdural puncture headache is very common in adults and has also been well-described in children and adolescents. ${ }^{19,20}$ Like adults, pediatric patients (girls > boys) may develop postdural puncture headache after diagnostic spinal punctures, spinal anesthesia, or inadvertent dural puncture after attempted epidural needle placement. An initial epidural blood patch using 0.2 to $0.3 \mathrm{~mL} \cdot \mathrm{kg}^{-1}$ of autologous blood completely abolished postural headache in more than $90 \%,{ }^{19,20}$ while a second epidural blood patch was effective in the remainder. In contrast to these observations, our patient did not sustain a needle punctureinduced dural injury, but rather suffered a larger $(0.5$ $\mathrm{cm})$ durotomy as a complication of microdiscectomy. Several authors ${ }^{1,7}$ have recommended prompt reoperation for repair of incidental durotomy in patients with postoperative CSF leak, but others ${ }^{4,5}$ have advocated a less aggressive approach. For example, Wang et $a l .^{4}$ reported that six of eight patients with CSF leak (characterized by postural headache and photophobia) after lumbar surgery experienced complete resolution of their symptoms and an absence of long-term 
sequelae with conservative management. These results stimulated our initial attempts to avoid the need for additional surgery by treating our patient with medical therapy and epidural blood patches. Indeed, the second epidural blood patch temporarily abolished our patient's symptoms, but, unfortunately, her symptoms recurred after intense physical activity.

An inadequate volume of injected epidural blood, physical factors preventing formation or retention of clot (e.g., coagulopathy, extensive tissue scarring), multiple CSF leaks, or inaccurate injection site may result in epidural blood patch failure. It appears likely that our patient's first blood patch may have been unsuccessful because post-surgical scarring prevented adequate distribution of epidural blood to the durotomy site. As also illustrated in our patient (Figure 3), CT guidance was shown to increase the efficacy of a repeat epidural blood patch, ${ }^{21}$ presumably by allowing visual confirmation of an adequate spread of blood throughout the region of the suspected dural tear. We suspect that extensive scarring and possible residual bone fragment(s) concomitant with physical activity may have contributed to the failure of the two epidural blood patches in our patient. No residual bone fragments were specifically identified during surgery, but extensive scarring may have obscured presence of such fragments. The recurrence of our patient's radicular complaints most likely resulted from persistent disc protrusion, pseudomeningocele, and presence of epidural blood that combined to produce pressure on the L5-S1 nerve roots. ${ }^{22}$ Surgical intervention was ultimately required for treatment of both the CSF leak and the recurrent radicular pain. Surgical repair of a recurrent CSF leak remains a definitive therapeutic intervention and must be considered if conservative therapy fails to prevent pseudomeningocele, arachnoiditis, meningitis, and CSF fistula formation. ${ }^{9}$ Nevertheless, adequate repair of inadvertent durotomy does not appear to influence long-term results of lumbar spine surgery. ${ }^{2}$ Our patient has done well since she was discharged from the hospital, without further recurrence of her original radicular complaints.

In summary, the current case emphasizes that delayed presentation of dural injury may occur after lumbar surgery. Epidural blood patches were performed, with and without CT guidance, that provided temporary relief of our patient's symptoms, but direct suture plication of the dural tear was eventually required for definitive treatment. Diagnosis and management of chronic CSF leak resulting from inadvertent durotomy pose a series of clinical challenges.

\section{References}

1 Eismont FJ, Wiesel SW, Rothman RH. Treatment of dural tears associated with spinal surgery. J Bone Joint Surg Am 1981; 63: 1132-6.

2 Jones AA, Stambough JL, Balderston RA, Rothman RH, Booth RE Jr. Long-term results of lumbar spine surgery complicated by unintended incidental durotomy. Spine 1989; 14: 443-6.

3 Stolke D, Sollman WP, Seifert V. Intra- and postoperative complications in lumbar disc surgery. Spine 1989; 14: 56-9.

4 Wang JC, Boblman HH, Riew KD. Dural tears secondary to operations on the lumbar spine. Management and results after a two-year-minimum follow-up of eighty-eight patients. J Bone Joint Surg Am 1998; 80: 1728-32.

5 Khan MH, Ribn J, Steele G, et al. Postoperative management protocol for incidental dural tears during degenerative lumbar spine surgery: a review of 3,183 consecutive degenerative lumbar cases. Spine 2006; 31: 2609-13.

6 Le AX, Rogers DE, Dawson EG, Kropf $M A$, De Grange $D A$, Delamarter $R B$. Unrecognized durotomy after lumbar discectomy: a report of four cases associated with the use of ADCON-L. Spine 2001; 26: 115-7.

7 Cammisa FP Jr, Girardi FP, Sangani PK, Parvataneni $H K$, Cadag S, Sandhu HS. Incidental durotomy in spine surgery. Spine 2000; 25: 2663-7.

8 Tafazal SI, Sell PJ. Incidental durotomy in lumbar spine surgery: incidence and management. Eur Spine J 2005; 14: 287-90.

9 Bossaco SJ, Gardner MJ, Guille JT. Evaluation and treatment of dural tears in lumbar spine surgery: a review. Clin Orthop Relat Res 2001; 389: 238-47.

10 Goodkin R, Laska LL. Unintended "incidental" durotomy during surgery of the lumbar spine: medicolegal implications. Surg Neurol 1995; 43: 4-12.

11 Schievink WI. Spontaneous spinal cerebrospinal fluid leaks: a review. Neurosurg Focus 2000; 9: e8.

12 Schievink WI. Spontaneous spinal cerebrospinal fluid leaks and intracranial hypotension. JAMA 2006; 295: 2286-96.

13 Milledge JT, Ades LC, Cooper MG, Jaumees A, Onikul $E$. Severe spontaneous intracranial hypotension and Marfan syndrome in an adolescent. J Paediatr Child Health 2005; 41: 68-71.

14 Bladen J, Moosajee M, Renowden S, Carter M, Sainsbury $C$, Jardine P. Neurological pictures. Spontaneous intracranial hypotension in adolescence. J Neurol Neurosurg Psychiatry 2007; 78: 167.

15 Johnson DB, Brennan P, Toland J, O'Dwyer AJ. Magnetic resonance imaging in the evaluation of cerebrospinal fluid fistulae. Clin Radiol 1996; 51: 837-41. 
16 Fishman RA, Dillon WP. Dural enhancement and cerebral displacement secondary to intracranial hypotension. Neurology 1993; 43: 609-11.

17 Fujimaki H, Saito N, Tosaka M, Tanaka $\Upsilon$, Horiguchi $K$, Sasaki T. Cerebrospinal fluid leak demonstrated by three-dimensional computed tomographic myelography in patients with spontaneous intracranial hypotension. Surg Neurol 2002; 58: 280-4.

18 Schievink WI, Tourje J. Intracranial hypotension without meningeal enhancement on magnetic resonance imaging. Case report. J Neurosurg 2000; 92: 475-7.

19 Ylonen P, Kokki H. Management of postdural puncture headache with epidural blood patch in children. Paediatr Anaesth 2002; 12: 526-9.

20 Ylonen P, Kokki H. Epidural blood patch for management of postdural puncture headache in adolescents. Acta Anaesthesiol Scand 2002; 46: 794-8.

21 Dillo W, Hollenhorst J, Brassel F, von Hof-Strobach K, Heidenreich F, Johannes $S$. Successful treatment of a spontaneous cervical cerebrospinal fluid leak with a CT guided epidural blood patch. J Neurol 2002; 249: 244-5.

22 O' Connor D, Maskery N, Griffiths WE. Pseudomeningocele nerve root entrapment after lumbar discectomy. Spine 1998; 23: 1501-2.

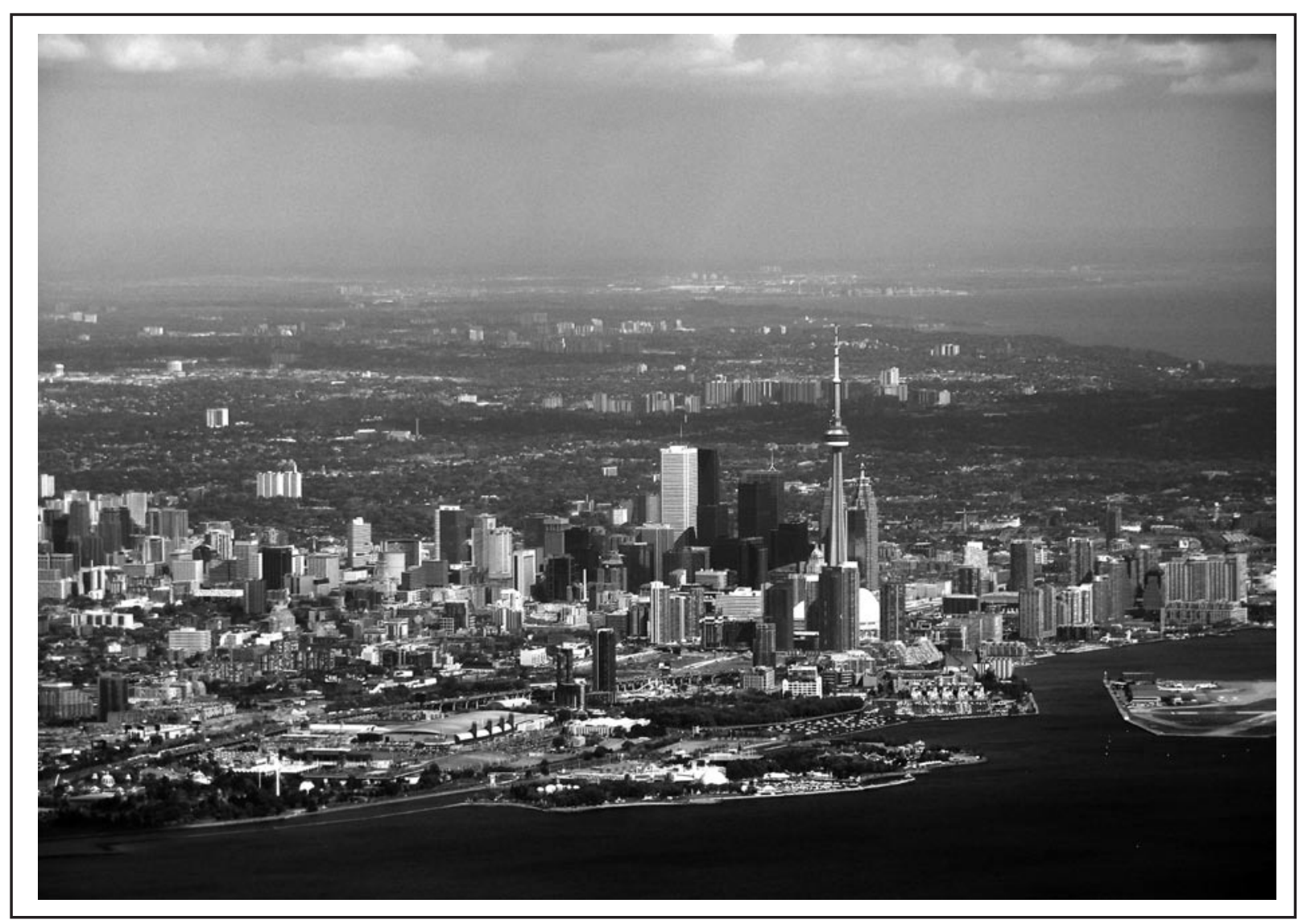

Toronto City Centre - Toronto, Ontario 